\title{
Mapping U-238 decay chain equilibrium state in thin sections of geo-materials by digital autoradiography and microprobe analysis
}

\section{Angileri, Axel}

2018-10

Angileri , A , Sardini , P , Donnard , J , Duval , S, Lefeuvre , H , Oger , T , Patrier , P , Rividi , N , Siitari-Kauppi , M , Toubon , H \& Descostes , M 2018 , ' Mapping U-238 decay chain equilibrium state in thin sections of geo-materials by digital autoradiography and microprobe analysis ' , Applied Radiation and Isotopes , vol. 140 , pp. 228-237 . https://doi.org/10.1016/j.apradiso.2018.06.018

http://hdl.handle.net/10138/322040

https://doi.org/10.1016/j.apradiso.2018.06.018

cc_by_nc_nd

acceptedVersion

Downloaded from Helda, University of Helsinki institutional repository.

This is an electronic reprint of the original article.

This reprint may differ from the original in pagination and typographic detail.

Please cite the original version. 

combined mapping approaches.

1 IC2MP Equipe HydrASA, Poitiers, France.

92 AREVA, Paris, France.

3 Ai4R SAS, Nantes, France.

4 Service Camparis, Paris, France.

5 Department of Chemistry, University of Helsinki, Finland.

Keywords: Uranium, alpha particle, secular equilibrium, radioactive disequilibrium, digital autoradiography

\section{Introduction}

The determination of the mobility and localization of ${ }^{238} \mathrm{U},{ }^{235} \mathrm{U}$ and ${ }^{232} \mathrm{Th}$ decay chains radionuclides is essential for various environmental issues such as actinide migration in subsurface geo-materials (soils, sediments etc), nuclear waste storage and related waste 
management and health issues (Morishita et al., 2014; Wertheim et al., 2010; Yamamoto and Ishibashi, 2015). Mine tailings generated by uranium extraction contain daughter elements of the ${ }^{238} \mathrm{U}$ disintegration chain. These elements are difficult to localize because: i) Mine waste is mainly composed of finely divided geo-materials and ii) the concentration of these elements is often well below the detection threshold of standard techniques.

The condition of secular equilibrium is defined by all radio-emitters in a decay chain having the same activity (Bourdon et al., 2003). When secular equilibrium is reached it is possible to calculate the quantity of each intermediate radionuclide based on the quantity (measured) of the parent nuclide. Nevertheless, natural and anthropic processes can generate fractionation of nuclides within the decay chain and produce disequilibrium between the radionuclides (Contreras et al., 2015; Štrok and Smodiš, 2010; Van Orman et al., 2006). This disequilibrium makes it impossible to quantify and localize intermediate radionuclides with a geochemical behaviour different from the parent element without using expensive and complex sequential extraction methods (Blanco et al., 2004; Schultz et al., 1998; Tessier et al., 1979).

Quantifying and localizing radium in geo-materials is of great interest for many application fields. While $U$ can be considered as a trace element in the environment, radium is an ultratrace element (in the range of ppt-ppq). The fate of radium in the environment is therefore constrained by its adsorption onto mineral surfaces (Ames et al., 1983; Reinoso-Maset and Ly, 2016; Sajih et al., 2014) and co-precipitation reactions (Curti et al., 2010; Gnanapragasam and Lewis, 1995; Lestini et al., 2013). At the same time, radium is an incompatible alkaline earth metal which has a significantly different geochemical behaviour from uranium which is an incompatible and refractory actinide (Bourdon et al., 2003).

Digital Autoradiography (DA) based on a Micro-Pattern Gas Detector (MPGD) technology is employed in biology and medical fields for quantitative mapping of beta emitters (Donnard et al., 2009a; 2009b; 2009c). The use of DA has recently been extended to the quantitative 
mapping of alpha emissions in geo-materials (Sardini et al., 2016). In order to locate and identify the equilibrium state of decay chains in rock sections and hard materials, this last paper suggests investigating the spatial correlation between alpha emission mapping and the elemental chemical mapping of uranium.

This work aims to present a new approach to localize and determine spatially the state of equilibrium of ${ }^{238} \mathrm{U}$ decay chains in hand-scale geological specimens. This approach is based on the combination of three independent measuring techniques combined with image processing: (1) elementary chemical mapping, (2) DA of alpha particle emissions and (3) conventional alpha spectrometry. First the methodology is applied to samples at secular equilibrium and then to samples of ground ore and fresh tailings obtained from the chemical extraction of $U$ from ore (Cominak mine, Niger).

\section{Materials and Methods}

\subsection{Materials}

The two sets of samples used in this work were polished thin sections. The first set comprised two uranium-rich rocks which had already been used by Sardini et al. (2016). One sample came from the Shea Creek (SC) area (Athabasca basin, Canada, explored by AREVA). The rock is highly silicified and altered, containing mostly quartz and clay minerals like illite. Accessory minerals like zircon, Fe-tourmaline, Fe-Ti oxide and rare detrital white micas are also present. The age of this mineralized rock is around $1.3 \mathrm{~Gy}$. (Kister, 2003; Kister et al., 2004; Laverret et al., 2010). The sample is cross cut by a one millimetre thick vein of uraninite $\left(\mathrm{UO}_{2}, 88.15 \mathrm{wt} \% \mathrm{U}\right)$. The second rock is from the Le Bernadan (LB) mine (France) and consists of a hydrothermally-altered episyenetic rock. Aggregates of needle-shaped $\beta$-uranophane crystals $\left(\mathrm{Ca}\left(\mathrm{UO}_{2}\right)_{2}\left[\mathrm{HSiO}_{4}\right]_{2} \cdot 5 \mathrm{H}_{2} \mathrm{O}, 60.7 \mathrm{wt} \% \mathrm{U}\right)$ are embedded in this quartz-feldspathic rock. 
The geological age of the mineralization is around $150 \mathrm{My}$ (Patrier et al., 1997). Both samples are natural, and are under secular equilibrium for the ${ }^{238} \mathrm{U}$ chain. Thorium is present in trace amounts in these rocks $(<0.07 \%)$.

The second set of samples comprised two components: a ground uranium ore and its related fresh tailing (Déjeant et al., 2016). The ore was sampled after grinding and before selective U extraction. Due to the samples being fragile, they were embedded in epoxy resin. The ore is a mixture of different ores from various $\mathrm{U}$ deposits (from the Cominak site (Niger)) with an age of $99 \mathrm{My}$. The ground ore is mainly composed of quartz and K-feldspar grains with a diameter of the order of tens to hundreds of microns. The main uranium-rich phase consists of uraninite grains $\left(\mathrm{UO}_{2}\right)$ with a diameter of tens to hundreds of microns. Scanning Electron Microscope (SEM) allowed the identification of other accessory phases in both samples, including pyrite, sphalerite, galena, zircon and barite. The matrix between the grains is essentially made up of fine mineral grains such as clay minerals (mainly kaolinite and illite), and micrometric fragments of quartz, K-feldspar and accessory phases. The mineralogy of the fresh tailings remains similar, with however a slight reduction of the grain diameter. The fine fraction is more numerousand the quantity of uraninite grains is drastically reduced. Fresh tailings do not yet contain neoformed crystalized gypsum. The bulk uranium content of the ore and the tailings is respectively 3060 ppm and 200 ppm (Déjeant, 2014). All polished thin sections (30 $\mu \mathrm{m}$ thickness) were carbon-coated.

\subsection{Methods}

\subsubsection{Digital autoradiography (DA) using a micro-pattern gas detector - The} $\underline{\text { Beaver }}{ }^{\mathrm{TM}}$

The Beaver ${ }^{\mathrm{TM}}$ is a real-time digital autoradiography device developed by Ai4r SAS (Nantes, France). This charge particle imager is based on the use of micromesh structures such as parallel ionization multipliers working in a proportional mode (Donnard et al., 2009a, 2009b; 
Thers et al., 2003). This device was especially designed for particles having a low penetrating power.

A sub-millimeter gap adjacent to the sample is used as an amplification volume. In the first stage, primary electrons released by beta and alpha particle interaction with gas atoms are multiplied thanks to an electric field between the sample (used as an electrode itself) and a micromesh. The second stage is a diffusion gap where the first stage electronic avalanche is spread into a large cloud. The last stage is an amplification and reading structure made by a second micromesh and a pixelated anode. Each detected disintegration is reconstructed and creates an image entry consisting of the $x$ and $y$ coordinates of the detected particle. The acquisition software Beavacq ${ }^{\mathrm{TM}}$ enables the real-time reconstruction and visualization of the radioactive emissions.

Only primary electron avalanches amplified twice induce sufficiently high pulses above the electronics threshold to be detected by the anode. This ensures a good spatial resolution reaching $20 \mu \mathrm{m}$ for tritium. The sensitivity of the detector is $5.10^{-4} \mathrm{cpm} / \mathrm{mm}^{2}\left({ }^{3} \mathrm{H}\right)$ and the device is insensitive to $\mathrm{X}$ and gamma rays.

The result of the beta and alpha mapping is a pixelated image where each pixel is a representation of the number of particles emitted during the experiment. It is possible to choose to detect alpha or beta particles separately by adjusting the amplification gains of the Beaver ${ }^{\mathrm{TM}}$. In a previous work (Sardini et al., 2016) it was noticed that $18 \%$ of alpha particles seemed not to be detected compared to alpha spectrometry counts. As suggested by these authors, a correction factor of $1.18 \pm 0.03$ was factored in to the Beaver ${ }^{\mathrm{TM}}$ counts to ensure a good comparison between the measured and the theoretical alpha particle counts (see below).

The total acquisition time was set to 243236 seconds (67.56 hours) to have reasonable uncertainty in each measured pixel (10 pulses $\left./ \mathrm{mm}^{2}\right)$ The chosen pixel size for the alpha maps 
was $20 \times 20 \mu \mathrm{m}$. The regions of interest (ROIs) studied in the thin sections were $80 \times 130$, $80 \times 170,128 \times 128$ and $100 \times 128$ pixels for the $\mathrm{SC}, \mathrm{LB}$, ore and fresh tailing samples, respectively. The contribution presented here in uses the spatial information stored by the maps to check and localize the equilibrium state of the decay chain in geo-materials.

\subsubsection{Elementary chemical analyses}

An electron microprobe combined with wavelength dispersive spectroscopy (WDS) was used during this work. The analyses were performed in the CAMPARIS facility, Pierre et Marie Curie University, Paris, using a CAMECA SX100 microprobe. The detection limit of U and Th is $100-200 \mathrm{ppm}$ for intermittent analysis (CAMPARIS information) and the interaction volume of the beam is about $5 \mu \mathrm{m}^{3}$ (Goldstein et al., 2007). Intermittent analyses were performed with a voltage of $15 \mathrm{keV}$, dwell time 180-240 seconds and a probe current of $15 \mathrm{nA}$ for $\mathrm{Si}, \mathrm{P}, \mathrm{Ca}$, Fe, Ti, Al, Mg, Na, K, Mn and $\mathrm{Pb}$ and $150 \mathrm{nA}$ for $\mathrm{U}$ and $\mathrm{Th}$. The chemical maps were made with a voltage of $15 \mathrm{keV}$ and a probe current of $298 \mathrm{nA}$. For the mapping, the analysis step was set to the pixel size of the alpha maps (i.e. $20 \mu \mathrm{m}$ ) in order to avoid interpolations during the numerical superimpositions of the $U$ and alpha maps. The dwell time was 0.2 seconds, and the detection limit of $U$ was estimated to be around 2000 ppm.

Based on the experimentally measured concentration of $U$ at each point of the maps, elementary chemical mapping enables the calculation pixel by pixel of the theoretical alpha activity assuming secular equilibrium (see above).

\subsubsection{Alpha spectrometry}

Alpha spectrometry is used to identify alpha emitting radionuclides using their energies because the kinetic energy of the alpha emissions is distinctive for each alpha emitting radionuclide. Their energy enables the identification of the parental nuclide (García-Toraño, 2006; Vajda et al., 2012). In addition the amount of radioactivity can be determined normally 
from massless samples (Gingell ). The alpha emission determined by the alpha spectrometer depends on the acquisition geometry. The distance between the sample and the detector window ( $23.9 \mathrm{~mm}$ in diameter) diameter was $8.8 \pm 0.2 \mathrm{~mm}$. A strict counting area from the samples was chosen by placing a $10 \mathrm{~mm}$ in diameter mask window on each sample surface. This mask restricted the alpha emissions from the sample to the detector window. The measured area was now the same size as it was chosen to determine in the digital autoradiography and the results were comparable. The energy spectrum presented in this work was obtained using a CANBERRA A450 PIPS® detector with an area of $450 \mathrm{~mm}^{2}$ and intrinsic energy resolution (FWHM) of 32 and $26 \mathrm{keV}$. The data acquisition and analysis were done with the MAESTRO for Windows® Model A65-332 software. The energy calibration was performed with a reference sample containing ${ }^{237} \mathrm{~Np}(\mathrm{E}=$ $4788 \mathrm{keV}, \mathrm{I}=47 \%),{ }^{241} \mathrm{Am}(\mathrm{E}=5486 \mathrm{keV}, \mathrm{I}=84.5 \%)$ and ${ }^{244} \mathrm{Cm}(\mathrm{E}=5805 \mathrm{keV}, \mathrm{I}=76.4 \%)$. The distance from source to detector was $8.4 \mathrm{~mm} \pm 0.2 \mathrm{~mm}$. The number of energy channels was 1024. s The acquisition time of SC and LB samples was 250000 seconds (69.44 h) which is close to the acquisition time with digital autoradiography. However, the acquisition time of ore and tailing samples was $1627000 \mathrm{~s}(451.94 \mathrm{~h})$ which was chosen knowing that the radioactivity of these samples was lower than in the SC and LB samples. . The acquisition times here are higher than those obtained by the Beaver ${ }^{\mathrm{TM}}$, also because of the average solid angle which is narrower than in the digital autoradiography.The the average solid angle; cc, was determined by setting the acquisition geometry in the AASI program.

$$
\text { Conventional alpha spectrometry is usually performed on "massless" samples which are }
$$
obtained by tedious chemical separations (Myllykylä et al. 2017)in such samples, alpha spectra show peaks. For thick samples like geological thin sections the alpha spectra show step-like shapes (Pöllänen et al. 2007). This is due to the energy loss of the alpha particles through the 
sample thickness and a well-defined simulation is crucial for analysing these step-like spectra coming from the thick samples.

The obtained spectra were adjusted using the "Advanced Alpha Spectrometry Simulation" (AASI) software (Siiskonen and Pöllänen, 2005). The resulting data enabled the evaluation of the activity of each radionuclide present in the sample. Secular equilibrium is confirmed for a given decay chain if all alpha emitters are present and have the same activity.

\subsubsection{Method for secular equilibrium state mapping}

The chosen approach to identify and locate the secular equilibrium state in geo-materials is a combination of three independent techniques: i) $\mathrm{U}$ and Th mapping by microprobe, ii) alpha particles mapping and counting by DA and iii) equilibrium state confirmation by alpha spectrometry.

\subsubsection{Conversion of chemical map into theoretical alpha map at equilibrium}

The pixel per pixel conversion of $\mathrm{U}$ content $\mathrm{C}_{\mathrm{x}}(\mathrm{wt} \%)$ to the alpha emission $\mathrm{N}_{\alpha}$ at secular equilibrium (counts per second, cps) stemming from the pixel surface was determined by the relationship described by Sardini et al. (2016). The mineral density ( $\rho$ ) and average range of alpha particles in the considered minerals $(\bar{R})$ are the most important parameters among other variables used in this calculation. ones. The contribution of ${ }^{235} \mathrm{U}$ was neglected, which would have increased $\mathrm{N}_{\alpha}$ to $5 \%$. For all samples, $\bar{R}$ was obtained by the calculation of the ranges of alpha particles for the 8 alpha emitters of the ${ }^{238}$ U chain, using SRIM (Ziegler et al., 2010). In this work the disintegration chain of ${ }^{232} \mathrm{Th}$ is neglected also because of the very low concentration of this radionuclide in the studied samples.

Application of this pixel per pixel conversion led to a theoretical alpha map assuming the secular equilibrium. Before the superimposition with the experimental alpha map, a 
Gaussian blur was introduced to the theoretical map in order to mimic the lateral dispersion of alpha particles emitted from the sample surface. Indeed the raw data extracted from the microprobe and converted into $\mathrm{cps} / \mathrm{mm}^{2}$ corresponded only to the uranium content of each pixel and did not take into account the dispersion of alpha and its contribution on adjacent pixels. To model this contribution a weak Gaussian blur with a kernel radius of 3 pixels $(60 \mu \mathrm{m})$ was applied to the theoretical alpha map. The radius of the filter was determined, using the uraninite vein. Some theoretical radioactivity profiles were modified with an increased filter radius size until a good fit with the experimental profile obtained by the Beaver ${ }^{\mathrm{TM}}$ was obtained.

\subsubsection{Superimposition of homologous images}

Using imaging tools the theoretical and the experimentally measured alpha emission maps were superimposed and compared. To avoid any problem of rotation during the superimposition, the samples were positioned parallel to the edge of the Beaver ${ }^{\mathrm{TM}}$ holder. The translation vector for superimposing the two homologous images was determined by minimizing the sum of the square of the distances separating certain homologous points, which were observed on both the theoretical and the experimental alpha maps. For instance, for ore and fresh tailing samples, hot spots corresponding to opaque $\mathrm{U}$ phases were used as homologous markers to determine the translation shift. The superimposition was performed using ImageJ software.

\subsubsection{Equilibrium state localization}

The superimposition of theoretical and experimental maps allows us to plot (i) measured alpha emissions versus theoretical alpha emissions for all points of both maps ("plot diagrams") and (ii) R-histograms of activity ratios. For plot diagrams, values near the " $\mathrm{x}=\mathrm{y}$ " line illustrate zones at secular equilibrium (theoretical emissions $=$ experimentally measured emissions). In contrast, values far from this "equilibrium line" illustrate zones of the section which are in 
radioactive disequilibrium (with a theoretical value higher or lower than the measured one). Some areas in a given plot diagram can be delineated. Points falling in these areas can be subsequently located in the studied section to determine the spatial distribution of the equilibrium state. The experimental alpha maps were blurred with a weak Gaussian filter (one pixel radius) to smooth and enhance the readability of the diagrams. Results were also illustrated by weighted histograms of the ratio $\mathrm{R}=$ theoretical alpha activity / measured alpha activity ("R-histograms"). The frequency on these histograms is the sum of the measured activity of all points for a given ratio $\mathrm{R}$ (x: ratio, $\mathrm{y}$ : sum of the measured activity). Because the theoretical and the measured activity are assumed to be equal at secular equilibrium, $\mathrm{R}>1$ would mean a depletion of alpha daughter radionuclides and $\mathrm{R}<1$ would mean a relative enrichment of daughter radionuclides.

\section{Results}

\subsection{Elementary chemical mapping}

The result of the microprobe analyses is a pixel by pixel map of uranium (wt\%). The sizes of the presented uranium maps are the same than as the ROI of the $\alpha$-maps with digital autoradiography (see section $\mathrm{xx}$ yy?). With the Image J software the $\mathrm{U}$ (wt\%) content was converted into a theoretical alpha emission at equilibrium $\left(\mathrm{cps} / \mathrm{mm}^{2}\right)$. Before conversion of the uranium map, a threshold was applied according to the detection limit of the $\mathrm{U}$ analyses. Using the Si elementary map, pure quartz was selected. For both samples, the distribution of U content in these selected grains presents a mean value of $1500 \mathrm{ppm}$. However, by point analyses, the content of $\mathrm{U}$ in quartz was found to be negligible. According to this observation we considered 2000 ppm of $U$ as a background level and $U$ content was set to 0 for points having a $U$ content lower than 2000 ppm. 
With the first set of samples, the correlation between the mineralogical observation and

the alpha map(s) made by the Beaver ${ }^{\mathrm{TM}}$ is clear. For the SC and LB samples the distribution of alpha emission fits well with the spatial distribution of U-rich mineral phases (see Sardini et al. 2016). The uraninite vein of SC can be immediately identified. The morphology of $\beta$ uranophane crystals of LB can be easily observed on the whole thin-section autoradiograph (see Fig. 1a-b). Measured emissions by the Beaver ${ }^{\mathrm{TM}}$ are $3.38 \times 10^{-2}$ and $8.35 \times 10^{-2} \mathrm{cps} / \mathrm{mm}^{2}$ respectively for the SC and LB samples.

For the ore and the fresh tailing samples the correlation with the alpha map is not as clear, due to the grain size of the material. The maps of both samples present a diffuse emission together with dispersed hot spots of alpha emission. For the ore this diffuse activity is due to the grinding process which generates a lot of fine grained particles (quartz, feldspars, clays and U-oxyde). In the ore thin section the hot spots correspond to opaque minerals identified as uranium oxide, Fig. 1c. Some hot spots detected by the Beaver ${ }^{\mathrm{TM}}$ correspond to very small Urich grains, and more problematically were sometimes not found by the SEM. The fresh tailing displayed a very similar alpha map, Fig. 1d. In this case the rock was however chemically treated to dissolve the U-rich phases and extract the uranium. The hot spots consistently correspond to uraninite grains included in a mineral (quartz, sulfate, sulfide) which isolated the uranium oxide from the leaching solution. In the fresh tailing sample the diffuse activity is presumed to be due to the presence of daughter elements of the ${ }^{238} \mathrm{U}$ decay chain. These daughter elements came from the fine particles of uranium oxide totally dissolved by the chemical extraction. Fine U-bearing mineral grains were however not observed in this fine grained matrix. Within these "diffuse" emissions, heterogeneities linked to the mineralogy can be observed (Fig. 2). Inactive zones, or zones with very low measured emissions, are mainly 
localized on quartz grains. Overall alpha emissions measured experimentally by the Beaver ${ }^{\mathrm{TM}}$ are shown in table 2.

\subsection{Alpha spectrometry analyses}

Using the AASI software it is possible to simulate the step-like alpha spectra observed experimentally, and determine the emission contribution of each radionuclide of the studied decay chain. Table 2 shows the calculated contribution of each radionuclide in the alpha simulated spectra using the AASI software. For the SC and LB samples, the fit shows that all radionuclide activities of the ${ }^{238} \mathrm{U}$ decay chain are the same, indicating that these two samples are at secular equilibrium. The fit of the alpha spectrum of the ore sample shows that the activities of the radionuclides are the same. For the fresh tailing sample the spectrum shows different emissions for each radionuclide, and the absence of ${ }^{238} U$ and ${ }^{234} U$ is observed. This sample is clearly in a state of radioactive disequilibrium.

Table 2: Alpha emissions by digital autoradiography and contribution of each alpha emitter in ${ }^{238} \mathrm{U}$ decay chain for all four studied samples. (1) Alpha emissions measured by Beaver ${ }^{\mathrm{TM}}$. (2) Alpha emissions deduced from $\mathrm{U}(\mathrm{wt} \%)$ contents. For the ore and the fresh tailing the bulk $\mathrm{U}$ content was 3060 ppm and 200 ppm. For SC and LB U content was measured with WDS and uranium mapping (Sardini et al., 2016).

\begin{tabular}{|c|c|c|c|c|c|c|c|c|c|c|}
\cline { 2 - 12 } \multicolumn{1}{c|}{} & \multicolumn{2}{c|}{$\begin{array}{c}\text { Alpha emissions } \\
\left(\mathrm{cps} / \mathrm{mm}^{2}\right)\end{array}$} & \multicolumn{9}{c|}{ Emission contribution of each alpha emitter in the ${ }^{238} \mathrm{U}$ decay } \\
chain $(\%)$
\end{tabular}


The emissions for all homologous pixels of measured and theoretical maps were compared using point diagrams.

The point diagrams of the LB and SC samples are given in Figures 3a-c. For these samples a clear correlation is shown between the theoretical and measured values. Using linear regression, the trend line gives a slope of $0.94\left(R^{2}=0.98\right)$ and $0.964\left(R^{2}=0.97\right)$ for $S C$ and $L B$, respectively. Three different populations of points can be observed in the plot diagrams (Fig 3). The highest experimental activities (" 1 " on Figure 3) range from 0.73 to $1.38 \mathrm{cps} / \mathrm{mm}^{2}$ for the LB sample and from 2 to $2.8 \mathrm{cps} / \mathrm{mm}^{2}$ for the SC sample. For both samples, these high activitieswere localized on a massive zone of U-rich minerals (uraninite and $\beta$-uranophane). Intermediate measured activities(“2" on Figure 3) range from 0.25 to $0.73 \mathrm{cps} / \mathrm{mm}^{2}$ for the LB sample and range from 0.25 to $2 \mathrm{cps} / \mathrm{mm}^{2}$ for the SC sample. On both samples, these intermediate activitiesare located on the periphery of the U-rich minerals. For the SC plot diagram, a slight curvature above the equilibrium line can be observed. The lowest measured activities(“3”" on Figure 3) range(s) from 0 to $0.25 \mathrm{cps} / \mathrm{mm}^{2}$ for both samples, and are located outside of the U-rich mineral zone.

For the $\mathrm{SC}$ and LB samples the R-histograms display a mean peak near $\mathrm{R}=1$. Evaluation of the data with a Gaussian distribution enabled a more accurate determination of $\mathrm{R}_{\text {mean }}$ for the massive uranium mineral and its periphery. $\mathrm{R}_{\text {mean }}$ for the U-rich minerals is 0.94 and 1.02 , for the LB and SC samples, respectively. For the periphery $\mathrm{R}_{\text {mean }}$ is equal to 0.71 for the LB sample and 1.13 for the SC sample (Fig. 3b-d). The external part of the vein (SC) shows a mean value of $\mathrm{R}$ equal to 0.75 and the minerals other than $\beta$-uranophane (LB) show a mean value of $\mathrm{R}$ near 0.64 . 
For the ore and fresh tailing samples majority of the points show lowactivities, ranging from 0 to $0.15 \mathrm{cps} / \mathrm{mm}^{2}$ (the Beaver ${ }^{\mathrm{TM}}$ activities) for the ore sample (representing $98.7 \%$ of the points) and 0 to $0.055 \mathrm{cps} / \mathrm{mm}^{2}$ for the fresh tailing sample (representing $96.8 \%$ of the points). The remaining points show higheractivities, ranging from 0.15 to $1.23 \mathrm{cps} / \mathrm{mm}^{2}$ for the ore and from 0.0055 to $0.3 \mathrm{cps} / \mathrm{mm}^{2}$ for the fresh tailing. Because a lot of points are in the low activityrange, $\log / \log$ inversed axes were used in these diagrams (Fig. 4). For both samples four main zones can be distinguished:

- Zone 1: The highest measured activities range from 1.56 to $0.76 \times 10^{-2} \mathrm{cps} / \mathrm{mm}^{2}$ for the ore sample and from 0.37 to $4.8 \times 10^{-2} \mathrm{cps} / \mathrm{mm}^{2}$ for the fresh tailing sample. Activities calculated using the uranium maps range from 1.31 to $0.76 \times 10^{-2} \mathrm{cps} / \mathrm{mm}^{2}$ for the ore sample and from 0.29 to $3.6 \times 10^{-2} \mathrm{cps} / \mathrm{mm}^{2}$ for the fresh tailing sample. These activities are localized on U-rich grains (uraninite) for both samples and represent respectively $4.5 \%$ and $3.3 \%$ percent of the mapped area for the ore and the fresh tailing.

- Zone 2: Intermediate measured activitiesrange from $6.8 \times 10^{-2}$ to $0.92 \times 10^{-2} \mathrm{cps} / \mathrm{mm}^{2}$ for the ore sample and from $1.28 \times 10^{-2}$ to $0.36 \times 10^{-3} \mathrm{cps} / \mathrm{mm}^{2}$ for the fresh tailing sample. For this group of points, theoretical activitiesranges from $8.7 \times 10^{-2}$ to $2 \times 10^{-2} \mathrm{cps} / \mathrm{mm}^{2}$ for the ore sample and from $1.8 \times 10^{-2}$ to $0.19 \times 10^{-2} \mathrm{cps} / \mathrm{mm}^{2}$ for the fresh tailing sample. These values are located on small U-rich grains on both samples. This zone represent $1.2 \%$ and $2.6 \%$ of the map for the ore and the fresh tailing respectively.

- Zone 3: This group is localized between high and low emission values, experimentally from $8.2 \times 10^{-2}$ to $0.86 \times 10^{-2} \mathrm{cps} / \mathrm{mm}^{2}$ for the ore sample and from $8.3 \times 10^{-2}$ to $1.3 \times 10^{-2}$ $\mathrm{cps} / \mathrm{mm}^{2}$ for the fresh tailing sample. For this group of points, theoretical activitiesranges from $2.7 \times 10^{-2}$ to $0.4 \times 10^{-2} \mathrm{cps} / \mathrm{mm}^{2}$ for the ore sample and from $1.2 \times 10^{-}$ ${ }^{2}$ to $0.58 \times 10^{-3} \mathrm{cps} / \mathrm{mm}^{2}$ for the fresh tailing sample. This group corresponds to a 
reconstruction artifact detected on the alpha map. On the maps this artifact represents $8.1 \%$ and $3.1 \%$ of the area for the ore sample and the fresh tailing, respectively. lower than $2 \times 10^{-2} \mathrm{cps} / \mathrm{mm}^{2}$ for the fresh tailing sample. The theoretical activitiesare centered near $\mathrm{R}=1$ areas (U-rich grains). lower than $2.6 \times 10^{-2} \mathrm{cps} / \mathrm{mm}^{2}$ for the ore sample and $2 \times 10^{-3} \mathrm{cps} / \mathrm{mm}^{2}$ for the fresh tailing sample. For the ore, the average experimental and theoretical activity is at equilibrium. For the tailing sample, the theoretical activitiesare clearly lower than the measured, the points being centered far from equilibrium. There is a difference of an order of magnitude between the measured and theoretical alpha counts. In the studied section, this group is localized outside the U-rich phases, corresponding to the diffuse alpha activity described above. The points of this group represent the larger fraction of points in the material map ( $86.2 \%$ for the ore and $91 \%$ for the fresh tailing).

For the ore and tailing samples, the R-histograms are more complex to interpret than for the SC and LB ones, cf. Fig. 5. These R-histograms have been determined on the four regions previously identified on the point diagrams. The $\mathrm{R}_{\text {mean }}$ for $\mathrm{U}$-grains (zone 1 ) is 0.9 for the ore sample and 0.75 for the fresh tailing sample. For both samples the small U-grains (zone 2) cannot be well matched to a Gaussian distribution and show a statistical mean equal to 0.91 for the ore and 1.06 for the tailing. The mineral matrix (zone 3) shows a mean value of R equal to 1.04 for the ore and 0.17 for the fresh tailing. For the fresh tailing sample the emissions histogram displays two modes corresponding to a low ratio zone (fine grain matrix) and zones 


\section{Discussion}

For SC and LB samples the trend line on the point diagram shows a slope of $0.94\left(\mathrm{R}^{2}\right.$ $=0.98)$ and $0.964\left(R^{2}=0.97\right)$, respectively. For both samples, 3 populations of points can be observed and are related to 3 zones, massive U-rich minerals, the periphery of the U-rich minerals, and the mineral matrix. The R-histograms show that, for both samples, the U-rich minerals and the periphery are at equilibrium. $\mathrm{R}_{\text {mean }}$ for the U-rich minerals is 0.94 and 1.02 , for the LB and SC samples, respectively. For the periphery $\mathrm{R}_{\text {mean }}$ is equal to 0.71 for the $\mathrm{LB}$ sample and 1.13 for the SC sample (Fig. 3). In the mineral matrix the mean value of R is slightly inferior to 1: for the $S C$ sample $R_{\text {mean }}=0.75$ and for the $L B$ sample $R_{\text {mean }}=0.64$. These deviations from the expected ratio $(\mathrm{R}=1)$ can be explained by a geometrical effect. As the alpha particle range is approximately $30 \mu \mathrm{m}$ in silicates it is possible to detect alpha particles emitted by a Ubearing mineral that is located under the surface of the thin section. The U-bearing mineral will produce detectable alpha particles but it will be undetectable by elementary chemical analysis. These geometrical situations would induce an under-estimation of the calculated emissions based on uranium content. A slight relative enrichment in daughter elements outside the U-rich phases can also be seen. These samples being relatively fractured, the daughter element enrichment could be due to the migration of ${ }^{222} \mathrm{Rn}$ from the U-rich phases to the mineral matrix through the open cracks.

For the SC sample a slight curvature can be observed on the point diagram. This is due to an important density variation in the sample. In the theoretical calculation the uraninite density was used in the whole chemical map. In this case the difference between the uraninite density $(\rho=8.72)$ and the quartz-rich matrix density $(\rho=2.7)$ will produce an overestimation of theoretical emissions on the interface between the two minerals. In the calcul, the product $[\boldsymbol{\rho} \times$

$377 \overline{\boldsymbol{R}}]$ is equal to $1.4 \times 10^{-2} \mathrm{~g} . \mathrm{cm}^{-2}$ for uraninite $\left(\rho=8.72 \mathrm{~g} \cdot \mathrm{cm}^{-3}, \bar{R}=16.5 \mu \mathrm{m}\right)$ and to $6 \times 10^{-3} \mathrm{~g} . \mathrm{cm}^{-2}$

378 for quartz $\left(\rho=2.7\right.$ g.cm $\left.{ }^{-3}, \bar{R}=22.4 \mu \mathrm{m}\right)$. This shows that $[\boldsymbol{\rho} \times \overline{\boldsymbol{R}}]$ has an important influence on 
the theoretical activity, a factor of $>2$ in this case. For $\beta$-uranophane, the curvature is not detected because the product $[\boldsymbol{\rho} \times \overline{\boldsymbol{R}}]$ is equal to $9 \times 10^{-3} \mathrm{~g} \cdot \mathrm{cm}^{-2}$ and it is closer to the quartz one. For these two samples secular equilibrium is easily identifiable using the presented approach. The use of mapping techniques provides the advantage, compared to bulk analysis, of localizing the heterogeneity of emissions on the geo-materials; but it is important to interpret the data carefully on the interfaces between the phases.

For ore and fresh tailing samples, R-histograms and point diagrams allow us to identify different zones according to their equilibrium state. For the ore and fresh tailing samples, the U-rich grains show an $R_{\text {mean }}$ value equal to 0.9 and 0.75 . These values are slightly under $R=1$. They can be explained by geometrical and petrographic effects. For both samples, the U-bearing mineral is made up of small uraninite grains (tens to hundreds microns). For the fresh tailing, the uraninite grains are smaller (tens microns or inferior) and always found in the other mineral phases (quartz, gypsum). The geometrical aspect already presented above is even more important in this case and probably induces an under-estimation of the calculated emissions from the $\mathrm{U}$ content. The mineral matrix (quartz grains and fine fraction) show an $\mathrm{R}_{\text {mean }}$ equal to 1.04 for the ore and 0.17 for the fresh tailing. These results are directly linked to the heterogeneity of the studied samples. For the ore sample all studied zones can be considered at secular equilibrium, even the mineral matrix. For the fresh tailing sample only the remaining U-rich grains are at equilibrium; conventional alpha spectrometry confirms the equilibrium for the ore but shows that the fresh tailing is in global disequilibrium. In this case the mapping approach enables the identification and localization of small mineral grains (grain size lower than $10 \mu \mathrm{m}$ ) at secular equilibrium in a sample in global disequilibrium. R-histograms are simple representations of emission distribution and enable the easy detection of the presence of zones in disequilibrium. 
This work shows that radioactive disequilibrium is present in the fine fraction for the fresh tailing sample. This disequilibrium illustrates a relative depletion in $\mathrm{U}$ and a relative enrichment of daughter nuclides, both of which are undetectable using a microprobe. Bulk alpha spectrometry, for its part, shows the absence of ${ }^{238} \mathrm{U}$ and ${ }^{234} \mathrm{U}$ but the presence of other daughter elements (see Table 2). The radioactive disequilibrium shown by alpha spectrometry is confirmed by the presented methodology. This approach managed successfully (1) to locate the disequilibrium in the sample and (2) to show the presence of remaining U-rich grains at secular equilibrium. These remaining grains represent $16.2 \%$ and $3.4 \%$ of the alpha activity for the ore and the fresh tailing, respectively.

The presented methodology is still under development and complementary studies must be performed to better determine the limits of the method. The alpha maps' spatial resolution must be studied with line sources. The Beaver ${ }^{\mathrm{TM}}$ was first developed for beta particle mapping on labelled biological samples with radio-emitters $\left({ }^{14} \mathrm{C},{ }^{3} \mathrm{H} \ldots\right)$ (Donnard et al., 2009). In rocks, $\beta$ mapping is also possible and could be potentially used as a tool for mapping the equilibrium state. This aspect is under investigation, but needs to be able to characterize beta trajectories in mineral matrices using sophisticated modelling tools. Raw data collected by the Beaver ${ }^{\mathrm{TM}}$ consists mainly of the particle coordinates $(x$ and $y$ ), the detection time and the charge induced on the pixelated anode. The spatial secular equilibrium state in geological thin sections is presented here for the first time at micrometre scale. Moreover, the influence of petrography and U-bearing mineral size could be modelized to better understand the variability of the $\mathrm{R}$ ratio in samples at secular equilibrium. Future work will focus on application fields concerning mining (exploration, environment) and alpha emitter localization and identification for nuclear waste management. 
429

A new method that combines quantitative digital autoradiography(Beaver $\left.{ }^{\mathrm{TM}}\right)$, elemental chemical mapping and bulk alpha spectrometrydeveloped by Sardini et al. (2016) was tested to precisely identify and locate the radioactive equilibrium state in rock thin sections. This work showed the potential of the approach as a new tool for locating the equilibrium state at the thin section scale. It was able to identify both equilibrium and disequilibrium at a micrometric scale in the same rock, bringing new information about the consequences for intermediate isotopes in industrial acidic extraction conditions. Future work will focus on method improvement (spatial resolution and shining effect, measurability, beta particles mapping) and application (environmental study and the links between alpha emissions and mineralogy).

\section{References}

Ames, L.L., McGarrah, J.E., Walker, B.A., Salter, P.F., 1983. Uranium and radium sorption on amorphous ferric oxyhydroxide. Chem. Geol. 40, 135-148.

Blanco, P., Tomé, F.V., Lozano, J.., 2004. Sequential extraction for radionuclide fractionation in soil samples: a comparative study. Appl. Radiat. Isot. 61, 345-350. doi:10.1016/j.apradiso.2004.03.006

Bourdon, B., Turner, S., Henderson, G.M., Lundstrom, C.C., 2003. Introduction to U-series geochemistry, in: Uranium-Series Geochemistry, Mineralogy \& Geochemistry. Bourdon, B., Turner, S., Henderson, G.M. \& Lundstrom, C.C., pp. 1-21.

Contreras, M., Pérez-López, R., Gázquez, M.J., Morales-Flórez, V., Santos, A., Esquivias, L., Bolívar, J.P., 2015. Fractionation and fluxes of metals and radionuclides during the recycling process of phosphogypsum wastes applied to mineral $\mathrm{CO} 2$ sequestration. Waste Manag. 45, 412-419. doi:10.1016/j.wasman.2015.06.046

Curti, E., Fujiwara, K., lijima, K., Tits, J., Cuesta, C., Kitamura, A., Glaus, M.A., Müller, W., 2010. Radium uptake during barite recrystallization at $23 \pm 2^{\circ} \mathrm{C}$ as a function of solution composition: An experimental 133Ba and 226Ra tracer study. Geochim. Cosmochim. Acta 74, 3553-3570. doi:10.1016/j.gca.2010.03.018

Déjeant, A., 2014. Réactivité de résidus miniers aprés leur entreposage : conséquences sur la spéciation de l'uranium (Mine uranifère de COMINAK, Niger). Paris Diderot, Paris VII.

Déjeant, A., Galoisy, L., Roy, R., Calas, G., Boekhout, F., Phrommavanh, V., Descostes, M., 2016. Evolution of uranium distribution and speciation in mill tailings, COMINAK 
Mine, Niger. Sci. Total Environ. 545-546, 340-352.

doi:10.1016/j.scitotenv.2015.12.027

Donnard, J., Arlicot, N., Berny, R., Carduner, H., Leray, P., Morteau, E., Servagent, N., Thers, D., 2009a. Advancements of labelled radio-pharmaceutics imaging with the PIMMPGD. J. Instrum. 4, P11022-P11022. doi:10.1088/1748-0221/4/11/P11022

Donnard, J., Berny, R., Carduner, H., Leray, P., Morteau, E., Provence, M., Servagent, N., Thers, D., 2009b. The micro-pattern gas detector PIM: A multi-modality solution for novel investigations in functional imaging. Nucl. Instrum. Methods Phys. Res. Sect. Accel. Spectrometers Detect. Assoc. Equip. 610, 158-160. doi:10.1016/j.nima.2009.05.186

Donnard, J., Thers, D., Servagent, N., Luquin, L., 2009c. High Spatial Resolution in $\beta$-Imaging With a PIM Device. IEEE Trans. Nucl. Sci. 56, 197-200. doi:10.1109/TNS.2008.2005673

García-Toraño, E., 2006. Current status of alpha-particle spectrometry. Appl. Radiat. Isot. 64, 1273-1280. doi:10.1016/j.apradiso.2006.02.034

Gnanapragasam, E.K., Lewis, B.-A.G., 1995. Elastic strain energy and the distribution coefficient of radium in solid solutions with calcium salts. Geochim. Cosmochim. Acta 59, 5103-5111.

Gingell T (2001) Thorium isotopic analysis by alpha spectrometry. Radiat Prot Dosim 97(2):109-116

Goldstein, J., Newbury, D., Joy, D., Lyman, C., Echlin, P., Lifshin, E., Sawyer, L., Micheal, J., 2007. Scanning Electron Microscopy and X-Ray Microanalysis, 3th ed. Springer.

Kister, P., 2003. Mobilité des éléments géochimiques dans un bassin sédimentaire clastique, du Protérozoïque à nos jours : la bassin Athabasca (Saskatchewen, Canada). Institut National Polytechnique de Lorraine.

Kister, P., Cuney, M., Golubev, V.N., Royer, J.-J., Le Carlier De Veslud, C., Rippert, J.-C., 2004. Radiogenic lead mobility in the Shea Creek unconformity-related uranium deposit (Saskatchewan, Canada): migration pathways and $\mathrm{Pb}$ loss quantification. Comptes Rendus Geosci. 336, 205-215. doi:10.1016/j.crte.2003.11.006

Laverret, E., Clauer, N., Fallick, A., Mercadier, J., Patrier, P., Beaufort, D., Bruneton, P., 2010. $\mathrm{K}-\mathrm{Ar}$ dating and $\mathrm{d} 180-\mathrm{dD}$ tracing of illitization within and outside the SheaCreek uranium prospect, Athabasca Basin, Canada. Appl. Geochem. 856-871.

Lestini, L., Beaucaire, C., Vercouter, T., Descostes, M., 2013. Radium Uptake by Recrystallized Gypsum: An Incorporation Study. Procedia Earth Planet. Sci. 7, 479-482. doi:10.1016/j.proeps.2013.03.002

Morishita, Y., Yamamoto, S., Izaki, K., Kaneko, J.H., Toi, K., Tsubota, Y., 2014. Development of a Si-PM based alpha camera for plutonium detection in nuclear fuel facilities. Nucl. Instrum. Methods Phys. Res. Sect. Accel. Spectrometers Detect. Assoc. Equip. 747, 81-86. doi:10.1016/j.nima.2013.12.052

E. Myllykyla, T. Lavonen L. Koivula K. Ollila M. Siitari-Kauppi, 2017. Dissolution of ThO2: study of dissolution process with initial 229Th spike, J Radioanal Nucl Chem, 311:225235Patrier, P., Beaufort, D., Bril, H., Bonhomme, M., Fouillac, A.M., Aumaître, R., 1997. Alteration-mineralization at the Bernardan $U$ deposit (Western Marche, France): The contribution of alteration petrology and crystal chemistry of secondary phases to a new genetic model. Econ. Geol. 448-467.

R Pöllänen, T Siiskonen, M MoringJ Juhanoja, 2007 Direct alpha spectrometry for characterising hot particle properties Radiation Measurements 4, 10 pp 1666-1673 
Reinoso-Maset, E., Ly, J., 2016. Study of uranium(VI) and radium(II) sorption at trace level on kaolinite using a multisite ion exchange model. J. Environ. Radioact. 157, 136-148. doi:10.1016/j.jenvrad.2016.03.014

Sajih, M., Bryan, N.D., Livens, F.R., Vaughan, D.J., Descostes, M., Phrommavanh, V., Nos, J., Morris, K., 2014. Adsorption of radium and barium on goethite and ferrihydrite: $A$ kinetic and surface complexation modelling study. Geochim. Cosmochim. Acta 146, 150-163. doi:10.1016/j.gca.2014.10.008

Sardini, P., Angileri, A., Descostes, M., Duval, S., Oger, T., Patrier, P., Rividi, N., Siitari-Kauppi, M., Toubon, H., Donnard, J., 2016. Quantitative autoradiography of alpha particle emission in geomaterials using the Beaver ${ }^{\mathrm{TM}}$ system. Nucl. Instrum. Methods Phys. Res. A.

Schultz, M.K., Burnett, W.C., Inn, K.G.M., 1998. Evaluation of a sequential method for determining actinide fractionation in soils and sediments. J. Environ. Radioact. 40, 155-174.

Siiskonen, T., Pöllänen, R., 2005. Advanced alpha-spectrometry simulation, Nuclear instruments and Methods in Physics Research.

Štrok, M., Smodiš, B., 2010. Fractionation of natural radionuclides in soils from the vicinity of a former uranium mine Žirovski vrh, Slovenia. J. Environ. Radioact. 101, 22-28. doi:10.1016/j.jenvrad.2009.08.006

Tessier, A., Campbell, P.G., Bisson, M., 1979. Sequential extraction procedure for the speciation of particulate trace metals. Anal. Chem. 51, 844-851.

Thers, D., Bretonniere, T., Charpak, G., Coulon, P., Leray, P., Drancourt, C., Le Guay, M., Lupone, S., Luquin, L., Mart??nez, G., Meynadier, M., Pichot, P., 2003. Parallel ionization multiplier (PIM): a new concept of gaseous detector for radiation detection improvement. Nucl. Instrum. Methods Phys. Res. Sect. Accel. Spectrometers Detect. Assoc. Equip. 504, 161-165. doi:10.1016/S0168-9002(03)00813-1

Vajda, N., Martin, P., Kim, C.-K., 2012. Alpha Spectrometry, in: Handbook of Radioactivity Analysis. Elsevier, pp. 363-422.

Van Orman, J.A., Saal, A.E., Bourdon, B., Hauri, E.H., 2006. Diffusive fractionation of U-series radionuclides during mantle melting and shallow-level melt-cumulate interaction. Geochim. Cosmochim. Acta 70, 4797-4812. doi:10.1016/j.gca.2006.07.005

Wertheim, D., Gillmore, G., Brown, L., Petford, N., 2010. A new method of imaging particle tracks in solid state nuclear track detectors: IMAGING PARTICLE TRACKS IN SOLID STATE NUCLEAR TRACK DETECTORS. J. Microsc. 237, 1-6. doi:10.1111/j.13652818.2009.03314.x

Yamamoto, S., Ishibashi, H., 2015. Development of a three-layer phoswich alpha-betagamma imaging detector. Nucl. Instrum. Methods Phys. Res. Sect. Accel. Spectrometers Detect. Assoc. Equip. 785, 129-134. doi:10.1016/j.nima.2015.02.062 

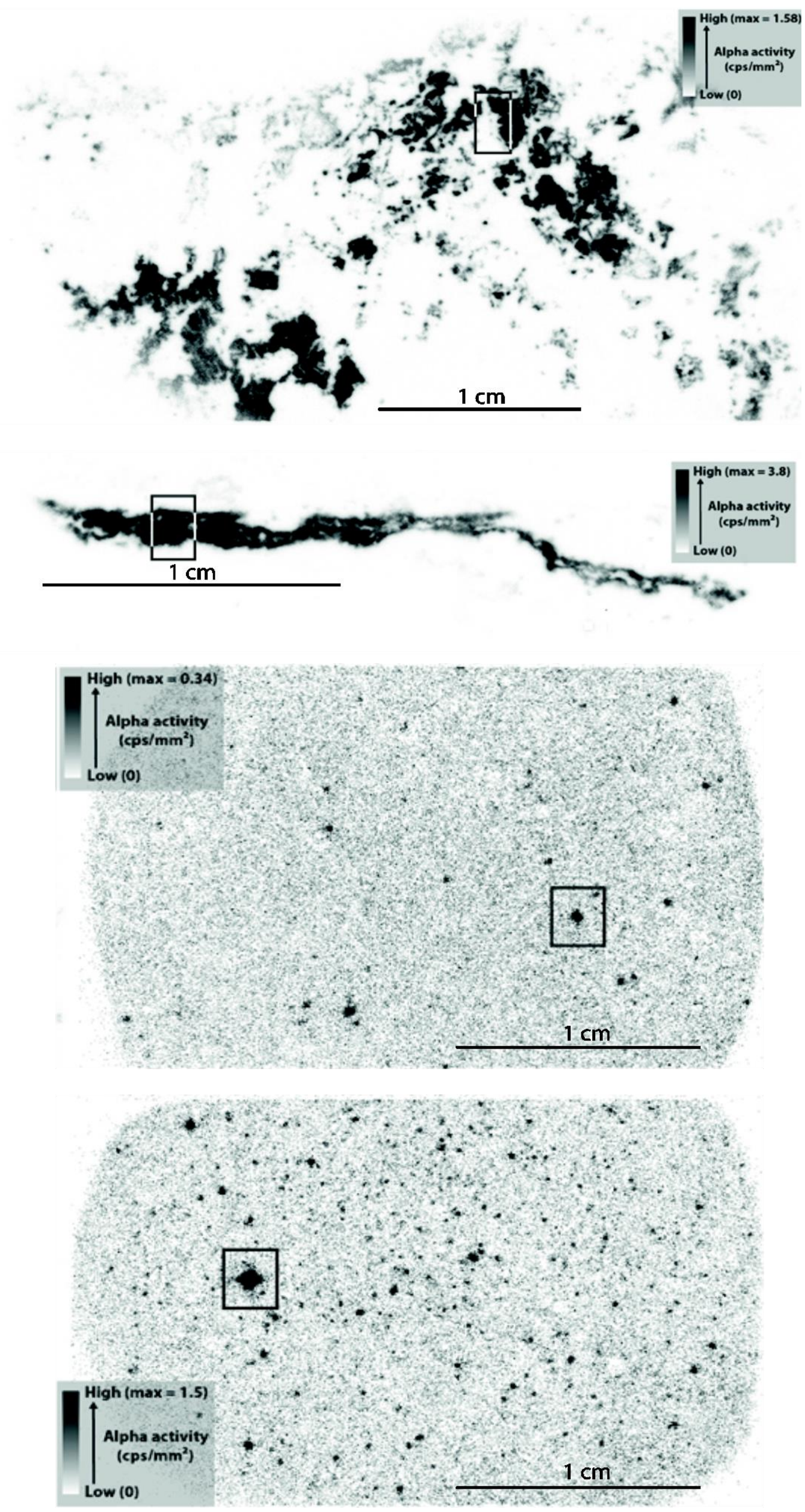
Figure 1: Alpha map of the different samples with the location of elementary chemical mapping of uranium (square). (a) Le Bernardan sample containing lot of $\beta$-uranophane crystals, (b) Shea Creek thin section with the uraninite vein, (c) and (d) are respectively the tailing and the ore samples having diffuse alpha activity and hot spots corresponding principally to uraninite grain. Scale bars $1 \mathrm{~cm}$.
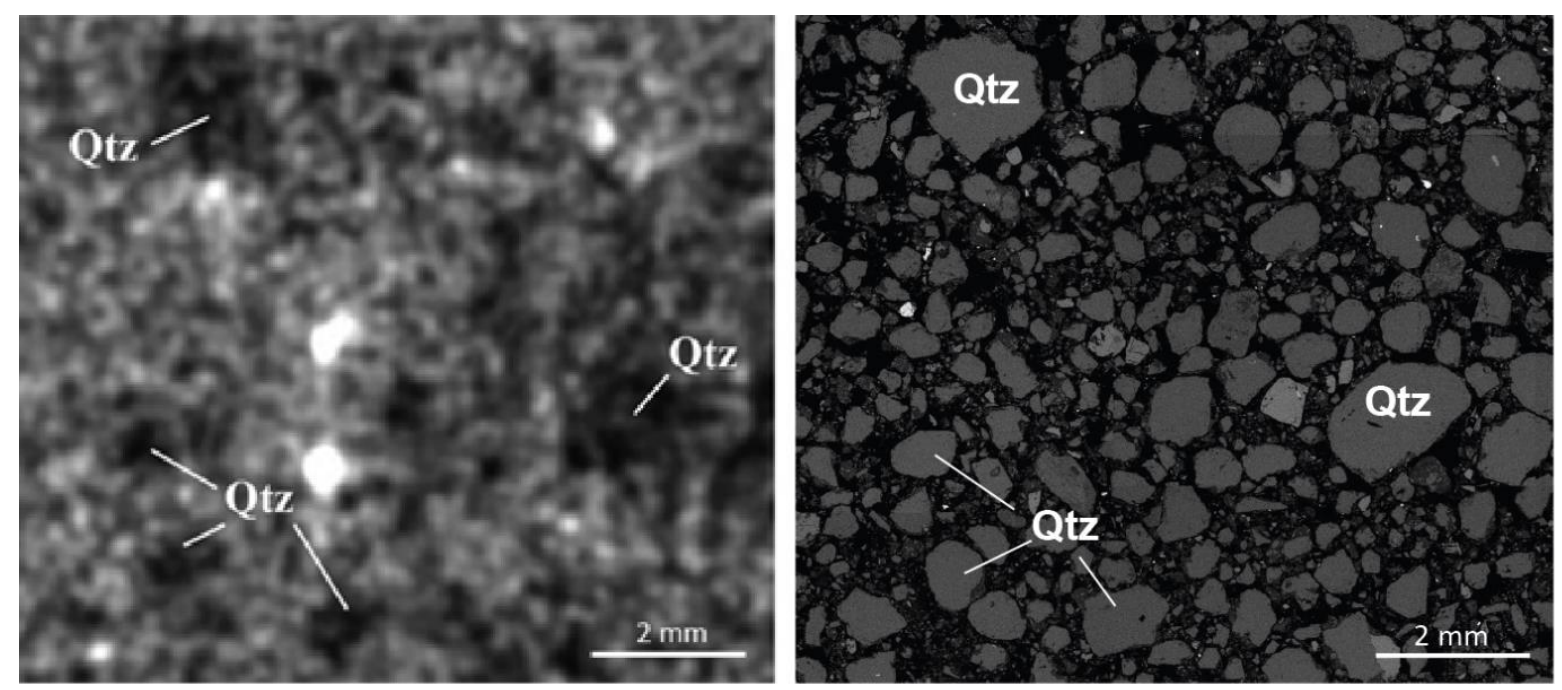

Figure 2: Alpha activity mapping on Beaver ${ }^{\mathrm{TM}}$ (left) shows a diffuse activity and hot spots on the ore and the fresh tailing (the present figure is related to fresh tailing sample). The diffuse alpha activity presents heterogeneity linked to the mineralogy. On SEM observation zone without activity or with very low activity are localized on quartz grains (rigth). 

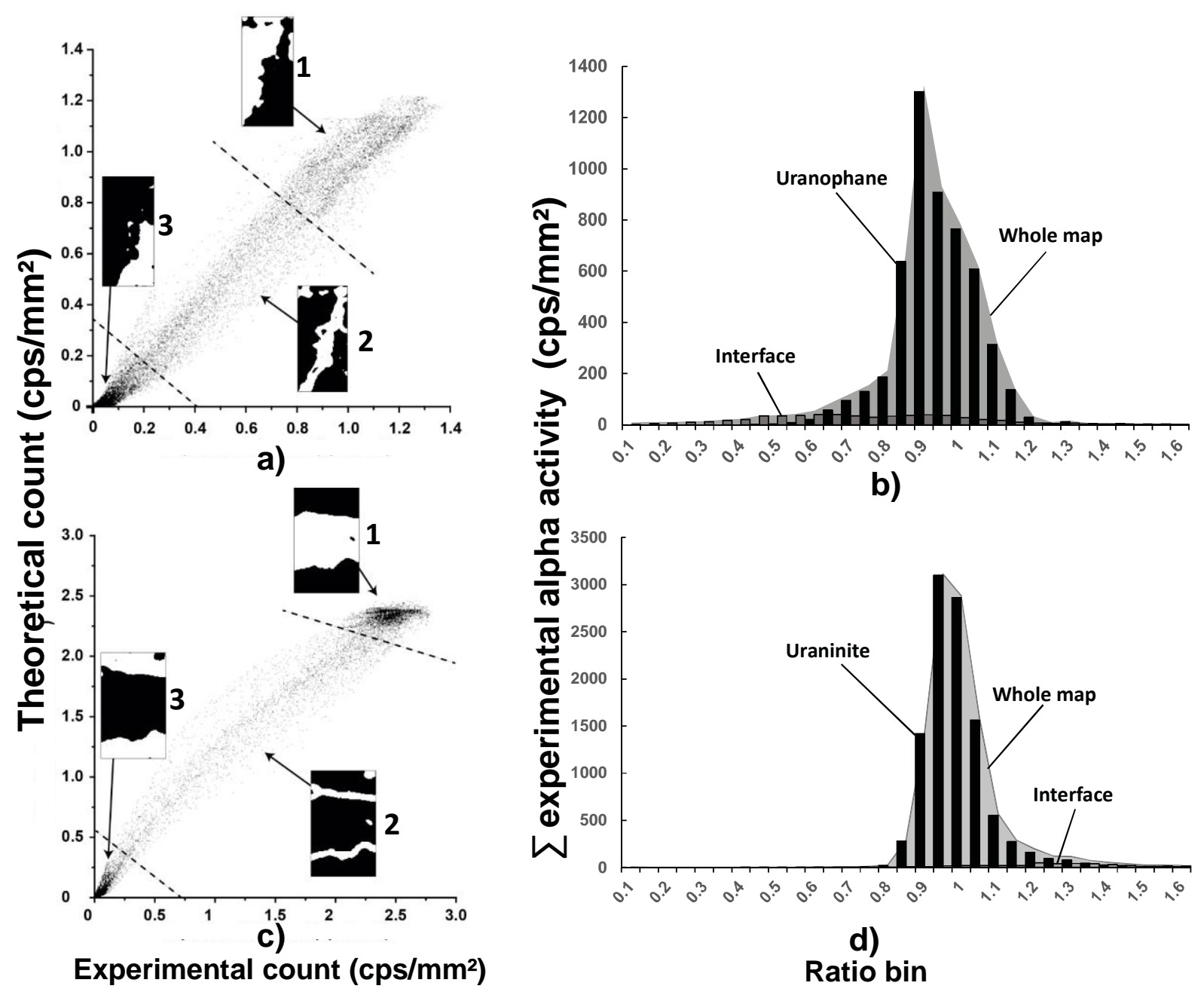

563 Figure 3: Point diagrams and R-histogram of LB (a, b) and SC (c, d) samples show three 564 populations of points corresponding to different zones of the map; 1: U-rich phases, 2: border 565 of the mineral and 3: external composed by the matrix. For both samples the points are near the equilibrium line. In R-histogram the activity of the mineral matrix (3) is too low to be 567 represented. 

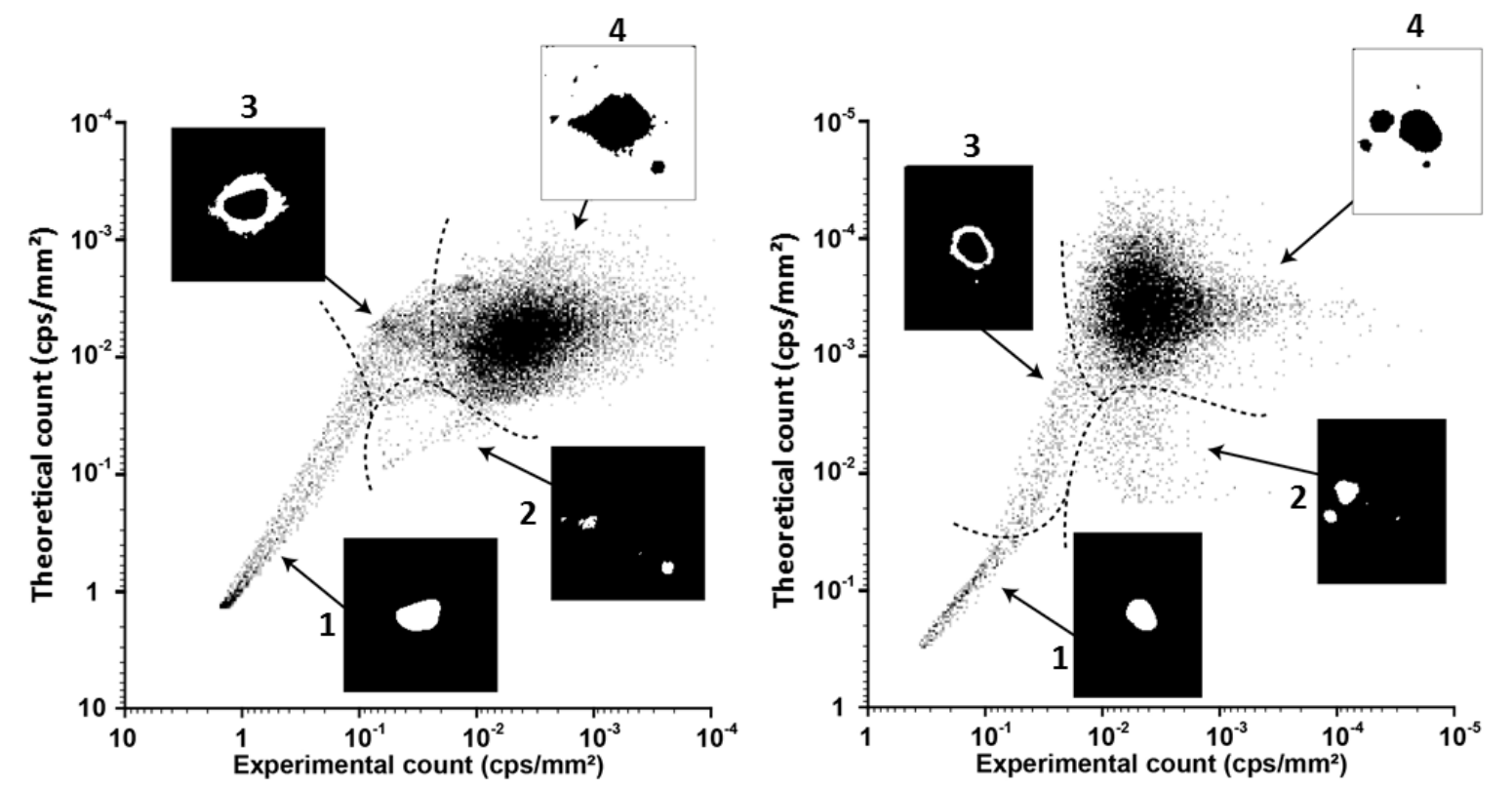

569 Figure 4: Point diagram of ore (left) and fresh tailing samples (right). The log/log scale permits 570 to enhance the visualization of points with low activity and their localization on the activity 571 map. On both samples four populations of point can be attributed to different zones of the map; 572 1: U-rich grain (uraninite), 2: smaller uraninite grains, 3: remaining reconstruction artefact and 573 4: low activity, fine grain mineral matrix. 


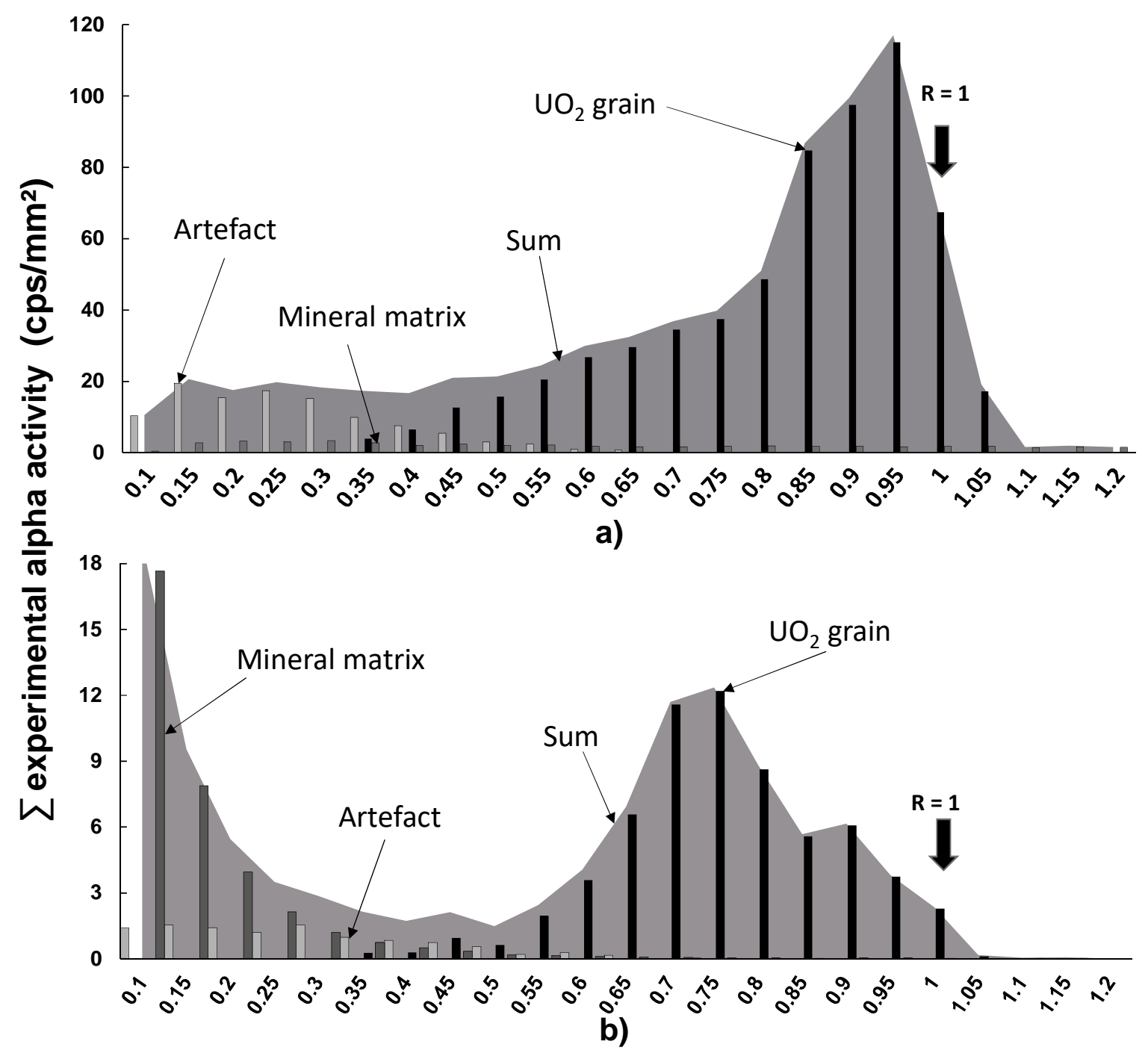

Figure 5: R-histograms ( $\mathrm{R}=$ theoretical activity/ experimental activity) are decomposed in different contributions, which were identified in plot diagrams. (a) is ore and (b) is fresh tailing related plot diagrams. 